\title{
Oportunidades educativas tras la pandemia: el tiempo es ahora
}

\section{Educational opportunities after the pandemic: the time is now}

\author{
Francisco J. Garrido Cisterna ${ }^{1,2}$, Juvenal A. Ríos Leal ${ }^{3,4}$
}

Señor Editor:

Ya se ha dicho en forma reiterada que esta encrucijada planetaria, la pandemia del COVID-19, se configura como la mayor crisis que la especie humana ha enfrentado en los últimos dos siglos, comparable solo con situaciones del calibre de las guerras mundiales o el cambio climático que hoy nos aqueja. No es majadero, referirse a ésta - la pandemia - como un problema multifactorial que cala en lo más hondo de las dimensiones sociales, educativas, económicas y por supuesto sanitarias de nuestras vidas. Como sistema educativo se nos impuso un obligado y vertiginoso desafío para adaptar rápidamente nuestra docencia a un formato on-line, incluyendo aquellos niveles educativos que nunca habríamos pensado en impartir completamente a distancia, como la educación parvularia, básica y media. En lo que respecta a la transformación digital de la educación superior y en especial, la formación de los profesionales de la salud, nos permitimos plantear algunas reflexiones sobre la implementación de la modalidad de aprendizaje on-line, que se extraen de las lecciones aprendidas de escuelas de Medicina de otros sectores del globo que, al poco andar de la crisis, generosamente ya han compartido a la comunidad médica mundial.

Conceptualmente, la educación en línea se define como el uso de Internet con fines educativos. Es una modalidad de enseñanza-aprendizaje que aspira a ser flexible, atractiva y centrada en el estudiante, fomentando la colaboración, comunicación e interacción entre los integrantes de la comunidad de aprendizaje (estudiantes, tutores y docentes) con el contenido. Por lo tanto, es más que un repositorio de recursos que el docente dispone para ser revisados por los estudiantes durante un determinado período de tiempo (Ellaway \& Masters, 2008). Los recursos digitales se organizan en entornos educativos virtuales y deben ser considerados un medio para el aprendizaje y no un fin en sí mismo: lecturas, presentaciones, videoconferencias, blogs, wikis, redes sociales, foros, podcast, portafolios, juegos, simulaciones, entre otras. Asimismo, existe un continuo entre una modalidad completamente presencial hasta los cursos en línea, pasando por una estrategia intermedia conocida como blended o híbrida, que combina ambas modalidades, procurando que gran parte del contenido teórico se aborde a distancia y los encuentros presenciales se reserven para aquellas experiencias de aprendizaje que requieran una interacción cara a cara, como son las actividades clínicas, visitas a terreno, seminarios de razonamiento clínico, laboratorios, sesiones de simulación clínica, entre otros.

La modalidad online ofrece múltiples ventajas para la formación de los profesionales de la salud, como la promoción de un aprendizaje autodirigido, a través de entornos de aprendizaje flexibles con disponibilidad permanente, además de involucrar a los estudiantes en una comunidad de aprendizaje colaborativo (Lewis et al., 2014). La tecnología está revolucionando la medicina, sin embargo, la manera de formar profesionales de la salud no ha cambiado al ritmo de los tiempos. Es cierto que la medicina clínica se aprende en el ambiente clínico y el encuentro con el paciente es muy valioso como experiencia educacional, pero hemos sido ineficientes como educadores en la gestión del tiempo y de los recursos humanos. Los recursos en línea se pueden utilizar para preparación de experiencias clínicas eficientes y de alto impacto educacional (Wilkinson, 2012)

En este contexto de pandemia, donde el diseño e implementación de la docencia virtual ha debido realizarse con premura y no exento de problemas, ha resultado fundamental aprehender las lecciones de los otros países. En este sentido, un grupo de educadores médicos de los Emiratos Árabes plantea algunas recomendaciones para su adopción en un contexto de urgencias, con el objeto de

(1) Departamento de Radiología y Diagnóstico por Imágenes, División de Imágenes, Laboratorios y Patología, Escuela de Medicina, Pontificia Universidad Católica de Chile.

(2) Centro de Educación Médica y Ciencias de la Salud, Facultad de Medicina, Pontificia Universidad Católica de Chile.

(3) Programas para el Futuro, Facultad de Estudios Interdisciplinarios, Escuela de Medicina, Facultad de Ciencias, Universidad Mayor, Chile.

(4) Escuela de Medicina, Facultad de Medicina y Ciencia, Universidad San Sebastián, Chile.

Autor de correspondencia: fjgarridoc@uc.cl 
sobrellevar con éxito el intempestivo cambio en la modalidad de aprendizaje en estos tiempos, las cuales son: (i) establecer un sentido de urgencia, que es crucial para el manejo del cambio, (ii) establecer un grupo de trabajo al interior de la facultad que lidere la transición de modalidad de aprendizaje presencial a online, (iii) realizar un análisis de necesidades de docentes y estudiantes (competencias digitales, recursos y equipamientos, entre otros), (iv) establecer y comunicar un plan de trabajo a la comunidad universitaria, (v) capacitar a los docentes en los roles del profesor virtual: pedagógico, administrador, social y técnico, (vi) consensuar los contenidos curriculares, decidiendo que se puede enseñar ahora, que se agrega, omite o pospone, (vii) establecer las estrategias de entrega de los contenidos (sincrónico o asincrónico), (viii) manejar el estrés de los estudiantes, tanto por la modalidad de aprendizaje como por la situación de emergencia sanitaria y sus repercusiones personales y/o familiares, (ix) promover la motivación y compromiso de los estudiantes, (x) planificar la evaluación de los aprendizajes, (xi) anticipar los potenciales problemas y estrategias de solución (problemas de conectividad, inestabilidad de las plataformas de comunicación, dificultades de docentes en particular, entre otros) y (xii) monitorizar y evaluar la implementación de la educación virtual y su mejora continua (Taha et al., 2020).

En este escenario de contingencia es el ciclo clínico el que se ve proporcionalmente más afectado, dado principalmente por su intrínseca manera de aprender basado en la interacción con los pacientes en el contexto clínico real. Entre las razones que se plantean para explicar el detrimento de la docencia clínica está la escasez de tiempo docente de los clínicos que participan directamente de la atención de los pacientes en la pandemia y la definitiva suspensión de las actividades asistenciales de los cursos clínicos de pregrado en los hospitales del mundo. Ante estas dificultades, surgen las siguientes preguntas e ideas para compensar con éxito la formación clínica; (i) promover una sensación de nueva normalidad al interior de los grupos internado, motivados por un tutor con dotes de liderazgo, (ii) implementar resolución de casos clínicos en sesiones virtuales, (iii) utilizar al máximo las herramientas digitales en salud, más allá de la sola telemedicina, (iv) entrenar el monitoreo de signos vitales y otro parámetros biomédicos de los pacientes, a través de la "internet de la cosas" y ( $v$ ) dar cumplimiento riguroso a todos los estándares bioéticos que exige el contexto de salud digital con estudiantes supervisados (Rose, 2020).

La implementación de la docencia virtual implica múltiples desafíos, tanto para los docentes como para los estudiantes. Por una parte, se requiere docentes capacitados en la planificación, diseño, implementación y evaluación en entornos educativos virtuales. Esto implica romper la tentación de realizar la misma clase presencial en una plataforma virtual. La modificación del plan del curso de manera creativa permitirá utilizar lo mejor de las herramientas digitales para promover aprendizaje profundos, colaborativos y significativos. Dado lo anterior, es un imperativo la incorporación de estas temáticas en los programas de formación de los futuros educadores de las profesiones de la salud: diseño instruccional, creación de recursos digitales, evaluación en entornos virtuales, feedback efectivo, entre otros. En la otra vereda, los estudiantes que cursan asignaturas con un componente virtual importante requieren desarrollar la capacidad de autorregulación y manejo efectivo del tiempo de trabajo, con el propósito de administrar adecuadamente su propio proceso de aprendizaje, y de integridad académica, sobre todo en los procesos de evaluación y generación de los productos que servirán como evidencias de su aprendizaje.

La pandemia por el COVID-19 impulsó una transformación digital de la educación en todos sus niveles, para la cual probablemente no estábamos preparados, pero que intuíamos, debía haberse dado hace mucho tiempo en educación superior. Qué duda cabe que, dentro de las barreras de implementación de esta modalidad educativa, el fantasma de la inequidad que arrastra nuestro sistema educativo hace varios años es un factor gravitante que aquí nuevamente se hace presente y de manera muy dolorosa, situaciones como el alto porcentaje de hogares sin conexión a internet y disponibilidad de computadores para alumnos de sectores vulnerables, sobre todo en lugares apartados y rurales, son situaciones que deberemos corregir en el más breve plazo. Es cierto que no es posible concebir un currículo completamente online, sobretodo en la formación de pregrado, sin embargo, podemos incorporar las buenas prácticas aprendidas durante este período, para implementarlas en nuestra docencia del día después de superar la pandemia. Así, habrá sido un virus que, entre otras cosas, catalizó la revolución de la educación, logrando una docencia acorde a los tiempos, centrada en el estudiante y apoyada en los recursos digitales, sin olvidar que el propósito final de todo nuestro quehacer es la formación de personas que estarán al servicio de la salud de la población.

Cordialmente,

\section{Francisco J. Garrido Cisterna Juvenal A. Ríos Leal}

Palabras clave: educación médica; aprendizaje en línea; transformación digital; COVID-19.

Keywords: medical education; online learning; digital transformation; COVID-19. 


\section{Referencias}

Ellaway R \& Masters K. (2008). AMEE Guide 32: E-Learning in medical education. Part 1: Learning, teaching and assessment. Medical Teacher 30,455-473.

Lewis KO, Cidon MJ, Seto TL, Chen H \& Mahan JD. (2014). Leveraging e-learning in medical education. Current Problems in Pediatric and Adolescent Health Care 44,150-163.
Rose S. (2020). Medical Student Education in the Time of COVID-19. JAMA 323, 2131-2132

Taha MH, Abdalla ME, Wadi M \& Khalafalla H. (2020). Curriculum delivery in Medical Education during an emergency: A guide based on the responses to the COVID-19 pandemic. MedEdPublish 9,69.

Wilkinson D. (2012). The future of medical education: all about being connected. The Ochsner Journal 12:300-301. 